\title{
Analysis of tool vibration and surface roughness with tool wear progression in hard turning: An experimental and statistical approach
}

\author{
Nitin Ambhore ${ }^{1,2^{*}}$, Dinesh Kamble ${ }^{2}$ and Satish Chinchanikar ${ }^{2}$ \\ ${ }^{1}$ Sinhgad College of Engineering, SP Pune University, Pune 41041, M.S., India \\ 2 Department of Mechanical Engineering, Vishwakarma Institute of Information Technology, SP Pune University, Pune, 411048, M.S., India
}

\begin{abstract}
The machined surface quality and dimensional accuracy obtained during hard turning is prominently gets affected due to tool wear and cutting tool vibrations. With this view, the results of tool wear progression on surface quality and acceleration amplitude is presented while machining AISI 52100 hard steel. Central Composite Rotatable Design (CCRD) is employed to develop experimental plan. The results reported that vibration signals sensed in a tangential direction $\left(V_{z}\right)$ are most sensitive and found higher than the vibrations in the feed direction $\left(V_{x}\right)$ and depth of cut direction $\left(V_{y}\right)$. The acceleration signals in all three directions are observed to increase with the advancement of tool wear and good surface finish is observed as tool wear progresses up-to $0.136 \mathrm{~mm}$. The vibration amplitude is discovered high in the range $3 \mathrm{kHz}-10 \mathrm{kHz}$ within selected cutting parameter range (cutting speed $60-180 \mathrm{~mm} / \mathrm{min}$, feed $0.1-0.5 \mathrm{~mm} / \mathrm{rev}$, depth of cut $0.1-0.5 \mathrm{~mm}$ ). The investigation is extended for the development of multiple regression models with regression coefficients value 0.9 . These models found statically significant and give dependable estimates between a tool vibrations and cutting parameters.
\end{abstract}

ARTICLE HISTORY

Revised: $5^{\text {th }}$ March 2019

Accepted: $8^{\text {th }}$ March 2019

\section{KEYWORDS}

Hard turning;

tool wear;

coated carbide;

surface roughness;

vibration:

ANOVA.

\section{INTRODUCTION}

Materials of hardness range within 46-68 HRC are designated as material of high hardness; these include various casehardened steels, hardened alloy steels and high-speed steels. These materials are preferred for their exceptional mechanical properties like high hardness; high wear opposition. These materials are extensively used in applications like chain sprocket, steel ball bearings, transmission shaft, valve casing, engine parts, gears, bearing, dies, punches, nozzles, railways components, helicopter camshaft [1-2]. The conventional processes for turning hardened steel are electricdischarge and grinding; and are in limited is use due to high tooling cost, low surface finish and material removal rate, faster wear. To overcome these drawbacks, these materials are turned with the super-hard cutting tools and process is referred as hard turning [3-4]. It is reported that this process is performed with no cooling media. This reduces post processing of cutting fluid in terms of its storage and dumping, and also decreases part cost up to 70\% [5-6]. But some analysts support utilization of cooling media in view of better surface finish and low tool vibrations [7-8].

Nowadays, carbide tools with the diverse coatings are utilized as a option for PCBN and ceramics tools. The much of the time utilized coatings incorporate TiN, TiAlN, TiCN, TiAlCN $\mathrm{Al}_{2} \mathrm{O}_{3}$ [9-13]. The performance of cutting tool with and without coatings in terms of cutting force [3-4], surface roughness [9-13], chip morphology [15] and acoustic emission [16] with various grades of the cutting tools is studied by different researchers and in-depth review related process parameter is reported by Ambhore et al. [17].

In hard turning, development of wear at the cutting edge of tool is the major drawback. The worn cutting edge develops more contact with the workpiece and thus increases friction between tool and workpiece. It results in more power consumption and induces vibrations during the cutting process. [18]. Forced vibration, is due to certain periodical forces that exist inside the machine that might be because of faulty gear drives, misalignment, unequal machine-device components and, so on. Vibrations in the metal cutting process are because of various attributes of the process such as varying cutting condition [11-12]. Self-excited vibrations are induced due to interaction between chip evacuation process and machine tool structure; and are considerably harming to a finished surface and results in drastic reduction in tool life. Non-homogeneity of workpiece material and improper system stiffness can brought more vibrations and noise in machining environment. The tool vibrations produce unacceptable part surface quality and unpredictable tool failure [1819]. Therefore such processes and associated vibrations are to be investigated deliberately.

The direct measurement of cutting tool vibration is difficult, hence related vibration parameters such as acceleration, velocity, displacement etc. are measured with the help of sensors. Piezoelectric accelerometers are widely used because of its very high dynamic range, high sensitivity and ability to operate at higher temperature. The nature of measured vibration is complex comprising various time dependable sinusoidal waves. Analysis of such response in frequency domain is extremely valuable since every parts of signal are more promptly revealed. The breaking of a complex signal into various sinusoidal components is achieved by transforming signals from time domain to frequency using Fast Fourier Transform analyzer [15]. Other techniques such as root mean square (RMS)[15], support vector machine[16], singular 
spectrum analysis (SSA)[8,20], etc are also used to analyze the vibration signals. FFT and RMS techniques have received a wide popularity among the researchers because of its fast data processing ability.

Zahia et al. [11] inferred that feed is overwhelming component impacting surface harshness, while vibrations in radial and tangential discovered an irrelevant impact on surface unpleasantness in turning 42CrMo4 hardened steel. Upadhyay et al. [12] investigated cutting tool acceleration in machining Ti-6Al-4V steel for in-process forecast of surface roughness. The in-process conjecture model discovered reliable with $\mathrm{R}^{2}$ esteem 0.93 . It is presumed that the feed is extraordinary effect on surface unpleasantness that spiral bearing increasing speeds. Grynal et al. [21] reported that flank wear is extraordinarily affected by machining factors. This investigation reasoned that surface is significantly affected by machining factors. The expansion in flank wears drives improvement in surface completion.

Bhuiyan et al. [15] captured vibration response while machining steel material ASSAB-705. The RMS vibration amplitude in directions namely feed and tangential has rational response to the flank wear progression. The increasing trend in vibration acceleration is observed as cutting speed increases. Prasad et al. [22] exhibited an inter-relationship between tool displacement and hardness. $\mathrm{R}^{2}$ value of developed model is observed 0.9. The ANOVA reported that tool displacement parameter is affected by depth of cut, cutting rate and material hardness.

In machining of high hardness steel using carbide coated tool, the majority of the investigations are found in associating surface harshness with tool vibration. However, the literature in correlating vibration with tool wear is hardly reported for hard turning. The objectives of the present study are to explore variation of tool vibration signals with the advancement of tool wear and, to perform analysis of variance for development of empirical relations. This investigation imparts the understanding of impact of cutting parameters on vibration signals and tool wear in turning hardened AISI52100 steel using low-cost PVD coated carbide tool.

\section{EXPERIMENTAL PROCEDURE}

\section{Workpiece and Tool material}

The trails are executed on AISI52100 alloy steel cylindrical bar. The length and diameter was $60 \mathrm{~mm}$ and $460 \mathrm{~mm}$ respectively. The hardness $54 \pm 2 \mathrm{HRC}$ is accomplished with help of heat treatment process. Then the rod is cleaned and put in to the machining environment. The insert is chosen based on tool maker's catalogue, workpiece hardness, and tool cost. The suitable grade is suggested as CNMG 120408 with tool holder PCLNR-25-25 M12. This is high quality insert of coating TiSiN-TiAlN and suitable for dry machining and interrupted cuts.

\section{Details of Experimentation}

In this investigation, the cutting variables shown in Table 1 are chosen on the idea of pilot experiments, accessible writing and tool maker's catalogue. In present work, experiments are planned by using CCRD. CCRD has indicated awesome potential to focus on the solidness district of the outline around a main issue controlled by its properties of rotatability and symmetry. Table 1 represent Coded levels of parameters.

Table 1. CCRD Coded levels.

\begin{tabular}{cccc}
\hline \multirow{2}{*}{ CCRD coded levels } & \multicolumn{3}{c}{ Factors } \\
\cline { 2 - 4 } & $\begin{array}{c}\text { Cutting Speed V, } \\
(\mathrm{m} / \mathrm{min})\end{array}$ & $\begin{array}{c}\text { Feed f, } \\
(\mathrm{mm} / \mathrm{rev})\end{array}$ & $\begin{array}{c}\text { Depth of cut d, } \\
(\mathrm{mm})\end{array}$ \\
\hline-1.682 & 60 & 0.1 & 0.1 \\
-1 & 90 & 0.2 & 0.2 \\
0 & 120 & 0.3 & 0.3 \\
1 & 150 & 0.4 & 0.4 \\
1.682 & 180 & 0.5 & 0.5 \\
\hline
\end{tabular}

The CCRD suggest twenty experimental sets which incorporates eight factorials, six axial and six same centre points set. Design Expert software is used to develop the experimental matrix. Machining response variables are studied by means of second order polynomial regression model [24],

$$
Y=a_{0}+\sum_{i=1}^{k} a_{i} x_{i}+\sum_{i=1}^{k} a_{i i} x_{i}^{2}+\sum_{i<j}^{k} a_{i j} x_{i} x_{j}
$$

where, $Y$ is the expected response, $x_{i}$ and $x_{j}$ are process variables, $a_{0}$ is constant, $a_{i j}, a_{i i}$, and $a_{i}$ signify second-order, quadratic and linear terms respectively.

The longitudinal turning tests are conducted on a rigid and high precision CNC lathe machine (Model: SimpleTurn5076). The machine is provided with spindle power $7.5 \mathrm{~kW}$ and speed of $2000 \mathrm{rpm}$. During machining test, accelerations in tangential, radial and feed directions are recorded using piezoelectric transducer (B\&K-4535-B001). The transducer signals are taken on personal computer via Bruel and Kjaer FFT analyzer. The software PHOTON-RT-Pro is used to analysis the vibration data. The roughness of newly developed surface is determined using instrument (Make-Taylor Hobson's Surtronic 
tester). Digital microscope (Dino-Lite) is utilized for the estimation of flank wear. Interrupted dry machining is performed using a fresh edge until the tool wear reaches $0.2 \mathrm{~mm}$ the event of the disastrous failure. The test setup is presented in Figure 1.

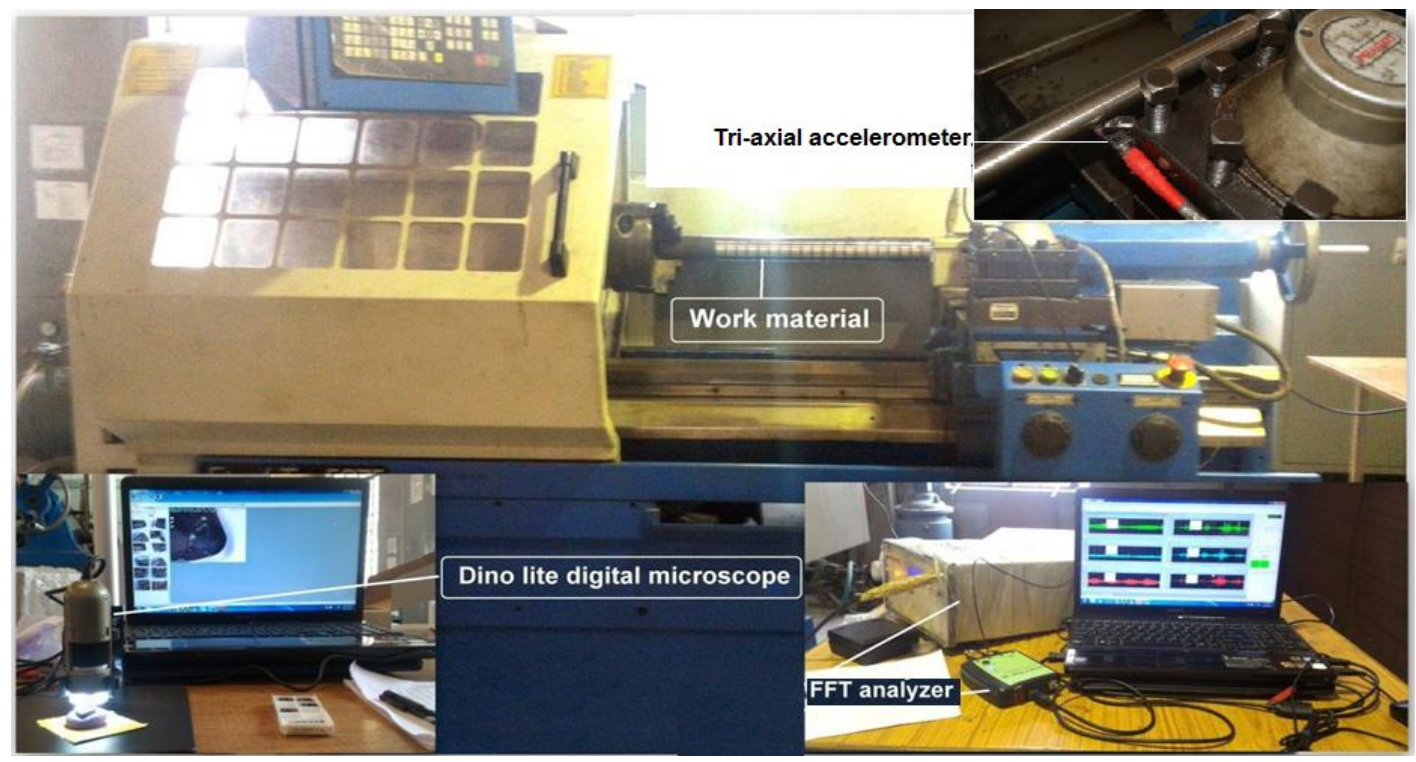

Figure 1. Experimental setup.

\section{RESULT AND DISCUSSION}

The recommended 20 sets of experiments are conducted and output parameter such as tool wear and tool acceleration are presented in Table 2. An analysis of variance (ANOVA) is reported to identify in order to study statistical significance in the measured cutting parameters, tool wear and acceleration response.

Table 2. Cutting parameters and results.

\begin{tabular}{ccccccccc}
\hline Run & \multicolumn{3}{c}{ Actual value } & & \multicolumn{3}{c}{ Response variables } \\
\cline { 2 - 3 } \cline { 6 - 7 } & $\mathrm{V}(\mathrm{m} / \mathrm{min})$ & $\begin{array}{c}\mathrm{f} \\
(\mathrm{mm} / \mathrm{rev})\end{array}$ & $\begin{array}{c}\mathrm{d} \\
(\mathrm{mm})\end{array}$ & & $\begin{array}{c}\mathrm{V}_{\mathrm{b}} \\
(\mathrm{mm})\end{array}$ & $\begin{array}{c}\mathrm{V}_{\mathrm{x}} \\
\left(\mathrm{mm} / \mathrm{s}^{2}\right)\end{array}$ & $\begin{array}{c}\mathrm{V}_{\mathrm{y}} \\
\left(\mathrm{mm} / \mathrm{s}^{2}\right)\end{array}$ & $\begin{array}{c}\mathrm{V}_{\mathrm{z}} \\
\left(\mathrm{mm} / \mathrm{s}^{2}\right)\end{array}$ \\
\hline 1 & 150 & 0.2 & 0.2 & & 0.18 & 0.05356 & 0.00679 & 0.00586 \\
2 & 150 & 0.4 & 0.2 & & 0.2 & 0.01651 & 0.07990 & 0.05020 \\
3 & 180 & 0.3 & 0.3 & & 0.17 & 0.00640 & 0.00630 & 0.00692 \\
4 & 120 & 0.3 & 0.3 & & 0.18 & 0.08242 & 0.07320 & 0.08218 \\
5 & 120 & 0.3 & 0.5 & & 0.15 & 0.04520 & 0.06330 & 0.04340 \\
6 & 90 & 0.4 & 0.4 & & 0.17 & 0.00500 & 0.05290 & 0.00800 \\
7 & 120 & 0.1 & 0.3 & & 0.16 & 0.04234 & 0.02410 & 0.03432 \\
8 & 120 & 0.3 & 0.3 & & 0.19 & 0.09242 & 0.08310 & 0.08360 \\
9 & 120 & 0.3 & 0.3 & & 0.19 & 0.07242 & 0.08130 & 0.08270 \\
10 & 120 & 0.5 & 0.3 & & 0.17 & 0.00840 & 0.08334 & 0.00530 \\
11 & 90 & 0.2 & 0.4 & & 0.17 & 0.02320 & 0.04410 & 0.06190 \\
12 & 120 & 0.3 & 0.1 & & 0.19 & 0.03446 & 0.03490 & 0.03952 \\
13 & 90 & 0.2 & 0.2 & & 0.19 & 0.01183 & 0.03124 & 0.04524 \\
14 & 60 & 0.3 & 0.3 & & 0.2 & 0.00031 & 0.00040 & 0.00045 \\
15 & 90 & 0.4 & 0.2 & & 0.18 & 0.00936 & 0.00979 & 0.01084 \\
16 & 120 & 0.3 & 0.3 & & 0.2 & 0.07342 & 0.07390 & 0.07930 \\
17 & 150 & 0.4 & 0.4 & & 0.19 & 0.01865 & 0.08227 & 0.02321 \\
18 & 150 & 0.2 & 0.4 & 0.13 & 0.02650 & 0.02640 & 0.03749 \\
19 & 120 & 0.3 & 0.3 & 0.18 & 0.06242 & 0.08340 & 0.09140 \\
20 & 120 & 0.3 & 0.3 & 0.18 & 0.08421 & 0.08360 & 0.08440 \\
\hline
\end{tabular}




\section{Analysis of Variance (ANOVA)}

The ANOVA provides correlation between parameters by multiple regressions and is that the additional reliable method to judge the superiority of a fitted model. In ANOVA table, the statistical significance of the fitted model is evaluated by p-value and F-value. If the p-value is less than 0.05 (or $95 \%$ confidence), the corresponding term signifies that the model terms are highly significant. It demonstrates that the terms considered within in the models have a major impact. When p-value is greater than 0.05 , the terms considered within the models does not have a considerable impact on responses and such terms are considered as insignificant terms for the model. The responses are analyzed using commercial available software (Design Expert). Table 3-7 illustrate ANOVA results for $V_{x}, V_{y}, V_{z}, V_{b}$ and $R_{a}$.

Table 3 presents ANOVA results for the vibration in feed direction $\left(\mathrm{V}_{\mathrm{x}}\right)$. It can be observed that quadratic term $\mathrm{V}^{2}$ have most statistical significance followed by $\mathrm{f}^{2}$ whereas ' $\mathrm{f}$ ' found not so much important. The term feed ( $\mathrm{f}$ ) also contribute the influence on $\mathrm{V}_{\mathrm{x}}$. The interaction $\mathrm{V} \times \mathrm{f}, \mathrm{V} \times \mathrm{d}$ and $\mathrm{f} \times \mathrm{d}$ observed to be just insignificant.

Table 3. ANOVA results for $\mathrm{V}_{\mathrm{x}}$.

\begin{tabular}{lcccccc}
\hline Source & $\begin{array}{c}\text { Sum of } \\
\text { Square }\end{array}$ & $\begin{array}{c}\text { Degree of } \\
\text { freedom }\end{array}$ & $\begin{array}{c}\text { Mean } \\
\text { Square }\end{array}$ & F-value & p-value & \\
\hline Model & 0.01529 & 9 & 0.00170 & 7.68049 & 0.0019 & significant \\
$\mathrm{V}$ & 0.00038 & 1 & 0.00038 & 1.71933 & 0.2191 & \\
$\mathrm{f}$ & 0.00111 & 1 & 0.00111 & 5.03189 & 0.0487 & \\
$\mathrm{~d}$ & 0.00000 & 1 & 0.00000 & 0.00361 & 0.9532 & \\
$\mathrm{~V} \times \mathrm{f}$ & 0.00007 & 1 & 0.00007 & 0.33170 & 0.5774 & \\
$\mathrm{~V} \times \mathrm{d}$ & 0.00013 & 1 & 0.00013 & 0.57611 & 0.4654 & \\
$\mathrm{f} \times \mathrm{d}$ & 0.00002 & 1 & 0.00002 & 0.10263 & 0.7553 & \\
$\mathrm{~V}^{\wedge} 2$ & 0.01015 & 1 & 0.01015 & 45.87238 & 0.0001 & \\
$\mathrm{f}^{\wedge} 2$ & 0.00535 & 1 & 0.00535 & 24.18142 & 0.0006 & \\
$\mathrm{~d}^{\wedge} 2$ & 0.00303 & 1 & 0.00303 & 13.68077 & 0.0041 & \\
Lack of Fit & 0.00165 & 5 & 0.00033 & 2.94474 & 0.1305 & not significant \\
Pure Error & 0.00056 & 5 & 0.00011 & & & \\
Total & 0.01750 & 19 & & & & \\
\hline
\end{tabular}

Table 4 illustrates analysis for the vibration in radial direction $\left(\mathrm{V}_{\mathrm{y}}\right)$, it was observed that $\mathrm{f}$ (feed) has the strong statistical relevance followed by ' $\mathrm{d}$ ' whereas the ' $\mathrm{V}$ ' was found less significant on the vibration in $\mathrm{V}_{\mathrm{y}}$. The product term $\mathrm{V}^{2}$ observed highest influence followed by $\mathrm{d}^{2}$ and $\mathrm{f}^{2}$. The product term $\mathrm{V} \times f$ also has significant effect on $\mathrm{V}_{\mathrm{y}}$ whereas term $\mathrm{V} \times \mathrm{d}$ and $\mathrm{f} \times \mathrm{d}$ are found to be insignificant.

When considering the vibration of cutting tool in tangential direction $\left(\mathrm{V}_{\mathrm{z}}\right.$ ), the result (Table 5) indicates that the product term $\mathrm{V}^{2}$ observed highest influence followed by $\mathrm{f}^{2}$ and $\mathrm{d}^{2}$. Additionally it can be revealed that feed has important influence on $V_{z}$. The terms ' $V$ ' and ' $d$ ' showed negligible influence on $V_{z}$. The interactions $V \times f$ and $f \times d$ are significant, while interaction $\mathrm{V} \times \mathrm{d}$ was observed to be insignificant.

Table 4. ANOVA results for $\mathrm{V}_{\mathrm{y}}$.

\begin{tabular}{lcccccc}
\hline Source & Sum of Square & $\begin{array}{c}\text { Degree of } \\
\text { freedom }\end{array}$ & $\begin{array}{c}\text { Mean } \\
\text { Square }\end{array}$ & F-value & p-value & \\
\hline Model & 0.01767 & 9 & 0.00196 & 29.77182 & 0.0001 & significant \\
$\mathrm{V}$ & 0.00030 & 1 & 0.00030 & 4.52981 & 0.0592 & \\
$\mathrm{f}$ & 0.00345 & 1 & 0.00345 & 52.25447 & 0.0001 & \\
$\mathrm{~d}$ & 0.00113 & 1 & 0.00113 & 17.20866 & 0.0020 & \\
$\mathrm{~V} \times \mathrm{f}$ & 0.00251 & 1 & 0.00251 & 38.02164 & 0.0001 & \\
$\mathrm{~V} \times \mathrm{d}$ & 0.00014 & 1 & 0.00014 & 2.19063 & 0.1697 & \\
$\mathrm{f} \times \mathrm{d}$ & 0.00002 & 1 & 0.00002 & 0.32060 & 0.5837 & \\
$\mathrm{~V} \wedge 2$ & 0.00960 & 1 & 0.00960 & 145.53916 & 0.0001 & \\
$\mathrm{f}^{\wedge} 2$ & 0.00121 & 1 & 0.00121 & 18.38743 & 0.0016 & \\
$\mathrm{~d}^{\wedge} 2$ & 0.00165 & 1 & 0.00165 & 25.01245 & 0.0005 & \\
Lack of Fit & 0.00054 & 5 & 0.00011 & 4.54635 & 0.0610 & not significant \\
Pure Error & 0.00012 & 5 & 0.00002 & & & \\
Total & 0.01833 & 19 & & & & \\
\hline
\end{tabular}


Table 5. ANOVA results for $\mathrm{V}_{\mathrm{z}}$.

\begin{tabular}{|c|c|c|c|c|c|c|}
\hline Source & Sum of Square & $\begin{array}{c}\text { Degree of } \\
\text { freedom }\end{array}$ & $\begin{array}{c}\text { Mean } \\
\text { Square }\end{array}$ & F-value & p-value & \\
\hline Model & 0.02035 & 9 & 0.00226 & 36.06874 & 0.0001 & significant \\
\hline V & 0.00000 & 1 & 0.00000 & 0.00333 & 0.9551 & \\
\hline $\mathrm{f}$ & 0.00085 & 1 & 0.00085 & 13.47918 & 0.0043 & \\
\hline d & 0.00004 & 1 & 0.00004 & 0.68554 & 0.4270 & \\
\hline$V \times f$ & 0.00175 & 1 & 0.00175 & 27.93333 & 0.0004 & \\
\hline $\mathrm{V} \times \mathrm{d}$ & 0.00001 & 1 & 0.00001 & 0.16800 & 0.6905 & \\
\hline$f \times d$ & 0.00076 & 1 & 0.00076 & 12.16675 & 0.0058 & \\
\hline $\mathrm{V}^{\wedge} 2$ & 0.01182 & 1 & 0.01182 & 188.60649 & 0.0001 & \\
\hline$f^{\wedge} 2$ & 0.00773 & 1 & 0.00773 & 123.33104 & 0.0001 & \\
\hline $\mathrm{d}^{\wedge} 2$ & 0.00370 & 1 & 0.00370 & 58.94891 & 0.0001 & \\
\hline Lack of Fit & 0.00047 & 5 & 0.00009 & 3.11753 & 0.1188 & not significant \\
\hline Pure Error & 0.00015 & 5 & 0.00003 & & & \\
\hline Total & 0.02098 & 19 & & & & \\
\hline
\end{tabular}

Table 6 present ANOVA results for tool wear $V_{b}$, revealed that cutting speed has the strongest influenced followed by ' $f$ ' and ' $d$ '. The interactions $V \times f$ and $V \times d$ were found less significant whereas interaction $f \times d$ observed to be immaterial. This is in great concurrence with the outcome presented by Suresh et al. It is to be noted that, tool wear is not depend only on cutting parameters, also depends on other factors such as tool grade and geometry, overhang length, workpiece hardness etc [22-23].

Table 6. ANOVA results for $\mathrm{V}_{\mathrm{b}}$.

\begin{tabular}{lcccccc}
\hline Source & Sum of Square & $\begin{array}{c}\text { Degree of } \\
\text { freedom }\end{array}$ & $\begin{array}{c}\text { Mean } \\
\text { Square }\end{array}$ & F-value & p-value & \\
\hline Model & 0.00563 & 9 & 0.000626 & 7.892855 & 0.0017 & significant \\
$\mathrm{V}$ & 0.00042 & 1 & 0.00042 & 5.302079 & 0.0441 & \\
$\mathrm{f}$ & 0.00038 & 1 & 0.00038 & 4.797419 & 0.0533 & \\
$\mathrm{~d}$ & 0.00156 & 1 & 0.00156 & 19.68487 & 0.0013 & \\
$\mathrm{~V} \times \mathrm{f}$ & 0.001301 & 1 & 0.001301 & 16.40774 & 0.0023 & \\
$\mathrm{~V} \times \mathrm{d}$ & 0.000128 & 1 & 0.000128 & 1.61491 & 0.2326 & \\
$\mathrm{f} \times \mathrm{d}$ & 0.000512 & 1 & 0.000512 & 6.459642 & 0.0293 & \\
$\mathrm{~V}^{\wedge} 2$ & $1.17 \mathrm{E}-06$ & 1 & $1.17 \mathrm{E}-06$ & 0.014788 & 0.9056 & \\
$\mathrm{f}^{\wedge} 2$ & 0.000971 & 1 & 0.000971 & 12.25639 & 0.0057 & \\
$\mathrm{~d}^{\wedge} 2$ & 0.00053 & 1 & 0.00053 & 6.685755 & 0.0272 & \\
Lack of Fit & 0.000488 & 5 & $9.76 \mathrm{E}-05$ & 1.600154 & 0.3093 & not significant \\
Pure Error & 0.000305 & 5 & $6.1 \mathrm{E}-05$ & & & \\
Total & 0.006423 & 19 & & & & \\
\hline
\end{tabular}

From the Table 7, it can be concluded that feed has the highest statistical significance followed by ' $V$ ' while parameter' $d$ ' was discover less effect on $\mathrm{R}_{\mathrm{a}}$. This shows acceptable concurrence with Auici et al.[3], D'Mello et al.[21] and Boy et al.[25]. The interactions $\mathrm{V} \times \mathrm{f}$ has statistical and physical significance on $\mathrm{R}_{\mathrm{a}}$. The interactions $\mathrm{V} \times \mathrm{d}$ and $\mathrm{f} \times \mathrm{d}$ were found to be less significant. The quadratic terms $V^{\wedge} 2$ and $d^{\wedge} 2$ also have significant interaction with $R_{a}$. It is concluded that the estimation of $\mathrm{R}_{\mathrm{a}}$ increment as feed and cutting speed increment. 
Table 7. ANOVA results for $\mathrm{R}_{\mathrm{a}}$.

\begin{tabular}{lcccccc}
\hline Source & Sum of Square & $\begin{array}{c}\text { Degree of } \\
\text { freedom }\end{array}$ & $\begin{array}{c}\text { Mean } \\
\text { Square }\end{array}$ & F-value & p-value & \\
\hline Model & 8.88663 & 9 & 0.98740 & 25.32339 & $<0.0001$ & significant \\
$\mathrm{V}$ & 0.19521 & 1 & 0.19521 & 5.00654 & 0.0492 & \\
$\mathrm{f}$ & 2.15253 & 1 & 2.15253 & 55.20474 & $<0.0001$ & \\
$\mathrm{~d}$ & 0.01601 & 1 & 0.01601 & 0.41073 & 0.5360 & \\
$\mathrm{~V} \times \mathrm{f}$ & 4.10211 & 1 & 4.10211 & 105.20451 & $<0.0001$ & \\
$\mathrm{~V} \times \mathrm{d}$ & 0.01447 & 1 & 0.01447 & 0.37103 & 0.5560 & \\
$\mathrm{f} \times \mathrm{d}$ & 0.00217 & 1 & 0.00217 & 0.05569 & 0.8182 & \\
$\mathrm{~V}^{\wedge} 2$ & 1.71517 & 1 & 1.71517 & 43.98812 & $<0.0001$ & \\
$\mathrm{f}^{\wedge} 2$ & 0.06177 & 1 & 0.06177 & 1.58408 & 0.2368 & \\
$\mathrm{~d}^{\wedge} 2$ & 1.14998 & 1 & 1.14998 & 29.49292 & 0.0003 & \\
Lack of Fit & 0.30476 & 5 & 0.06095 & 3.57892 & 0.0940 & not significant \\
Pure Error & 0.08515 & 5 & 0.01703 & & & \\
Total & 9.27654 & 19 & & & & \\
\hline
\end{tabular}

\section{Regression Modeling}

The aim of this research to analyze tool acceleration, surface roughness, and tool wear through predictive modeling. The multiple regression method of order two is implemented to develop models for $\mathrm{R}_{\mathrm{a}}, \mathrm{V}_{\mathrm{x}}, \mathrm{V}_{\mathrm{y}}, \mathrm{V}_{\mathrm{z}}$ and $\mathrm{V}_{\mathrm{b}}$ and are presented in Equations. (2-6)

$$
\begin{gathered}
R_{a}=-0.14919 * V-28.44322 * f-15.34347 * d+0.23869 * f * V+0.014175 * d * V \\
+1.64750 * d * f+0.000290205 * V^{2}+4.95641 f^{2}+21.38641 * d^{2}+16.87013 \\
V_{\mathrm{x}}=6.22191 E-3 * V+0.861 * f+0.770 * d-1.00954 E-003 * V * f-1.33046 E \\
-003 * V * d+0.169 * f * d-2.23224 E-5 * V^{2}-1.45864 * f^{2}-1.09714 * d^{2}-0.54072 \\
V_{y}=4.00862 E-03 * V-0.193 * f+0.691 * d+5.90113 E-003 * V^{*} f-1.4164 E-3 * V * d \\
+0.1625 * d * f-2.17083 E-005 * V^{2}-0.69445 * f^{2}-0.80995 * d^{2}-0.2796 \\
V_{z}=+4.42197 E-003 * V+0.681 * f+1.083 * d+4.93181 E-003 * V * f-3.8247 E-4 * d^{*} V \\
-0.9765 * d * f-2.40957 E-005 * V^{2}-1.75364 * f^{2}-1.21239 * d^{2}-0.43577 \\
V_{b}=+0.004536 * V+0.3702 * f+0.4345 * d+0.000708 * V * f-0.000375 * V * d \\
-0.062500 * d * f-0.000013 * V^{2}-0.422727 * f^{2}-0.393977 * d^{2}-0.376932
\end{gathered}
$$

The correctness of developed model is verified by means of regression coefficient $\left(\mathrm{R}^{2}\right)$. The $\mathrm{R}^{2}$ esteem near to one is alluring and the model represent much reliable. In other words, when $\mathrm{R}^{2}$ value approaches unity, higher the model fits the experimental data. The $\mathrm{R}^{2}$ value for $\mathrm{R}_{\mathrm{a}}, \mathrm{V}_{\mathrm{x}}, \mathrm{V}_{\mathrm{y}}, \mathrm{V}_{\mathrm{z}}$, and $\mathrm{V}_{\mathrm{b}}$ is found as $0.95,0.87,0.96,0.97$, and 0.87 respectively which suggest that the created models are statically noteworthy and can give solid appraisals within the limits of factor considered. The diagnostic checking of models is done with the help of normal residuals plot. Figure 2 show residual plots for $\mathrm{R}_{\mathrm{a}}$ and $\mathrm{V}_{\mathrm{x}}$. The plot reveals that the residuals lie on the brink of line which illustrates that error distributed normally and therefore the model does not indicate any inadequacy and provide the reliable prediction. 

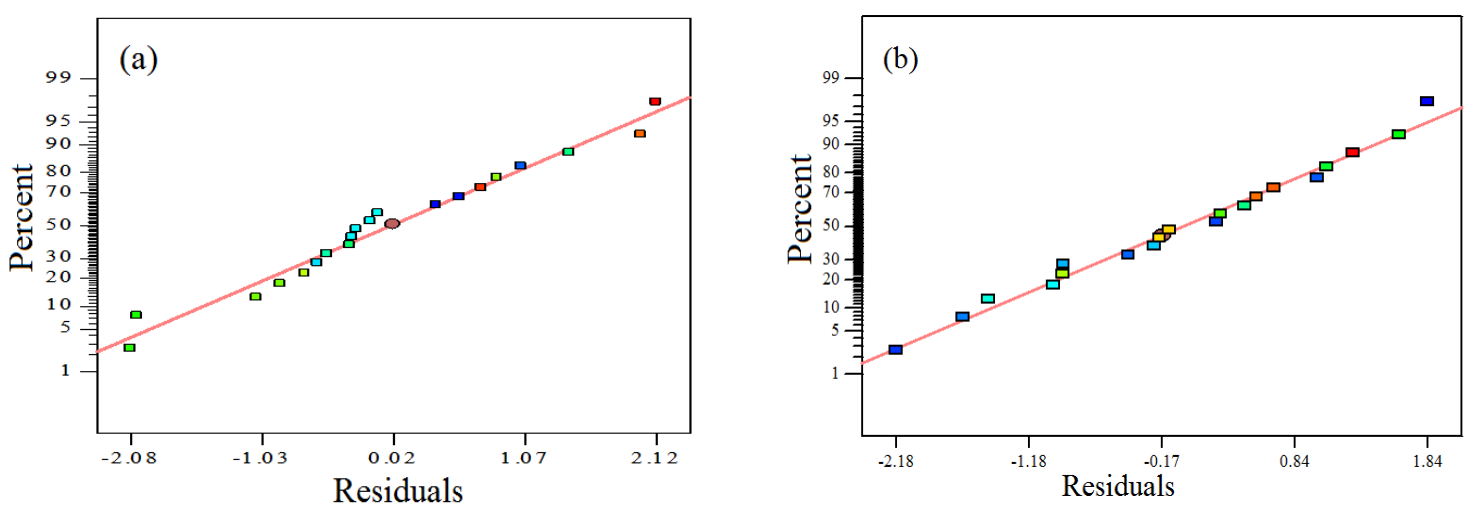

Figure 2. Residuals plot for (a) $\mathrm{R}_{\mathrm{a}}$ (b) $\mathrm{V}_{\mathrm{x}}$.

Figure 3 explores residuals analysis for $\mathrm{V}_{\mathrm{x}}$ and $\mathrm{V}_{\mathrm{b}}$ with respect to twenty cutting conditions. The residuals don't show any undeniable pattern and are appropriated in both positive and negative both sides. This infers the model is sufficient and there is no motivation to associate any infringement.
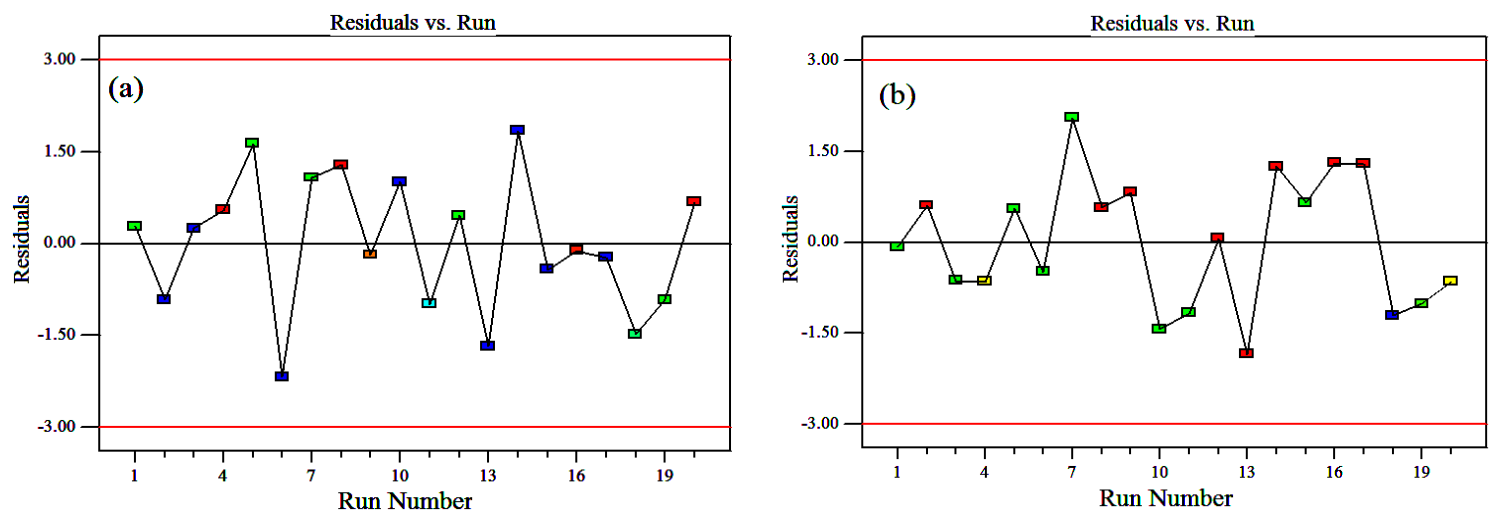

Figure 3. Normal probability of residuals (a) $V_{x}$ (b) $V_{b}$.

In addition to this, optimization is carried out to achieve a better product quality with minimum tool vibration. In the present study, surface roughness, and $\mathrm{V}_{\mathrm{x}}, \mathrm{V}_{\mathrm{y}}$ and $\mathrm{V}_{\mathrm{z}}$ were targeted to the minimum, keeping other variable in range. The optimized tool acceleration is found as, $V_{x}=0.0232 \mathrm{~mm} / \mathrm{sec}^{2}, V_{y}=-0.0044 \mathrm{~mm} / \mathrm{sec}^{2}$ and $V_{z}=0.0167 \mathrm{~mm} / \mathrm{sec}^{2}$. The optimized $R_{a}$ value is observed 0.7 micrometer and cutting speed $125.68 \mathrm{~m} / \mathrm{min}, \mathrm{f}=0.18 \mathrm{~mm} / \mathrm{rev}$, and d=0.42 mm. Figure 4 presents bar graph of desirability for selected cutting condition and the responses together with a combined desirability 0.9108 .

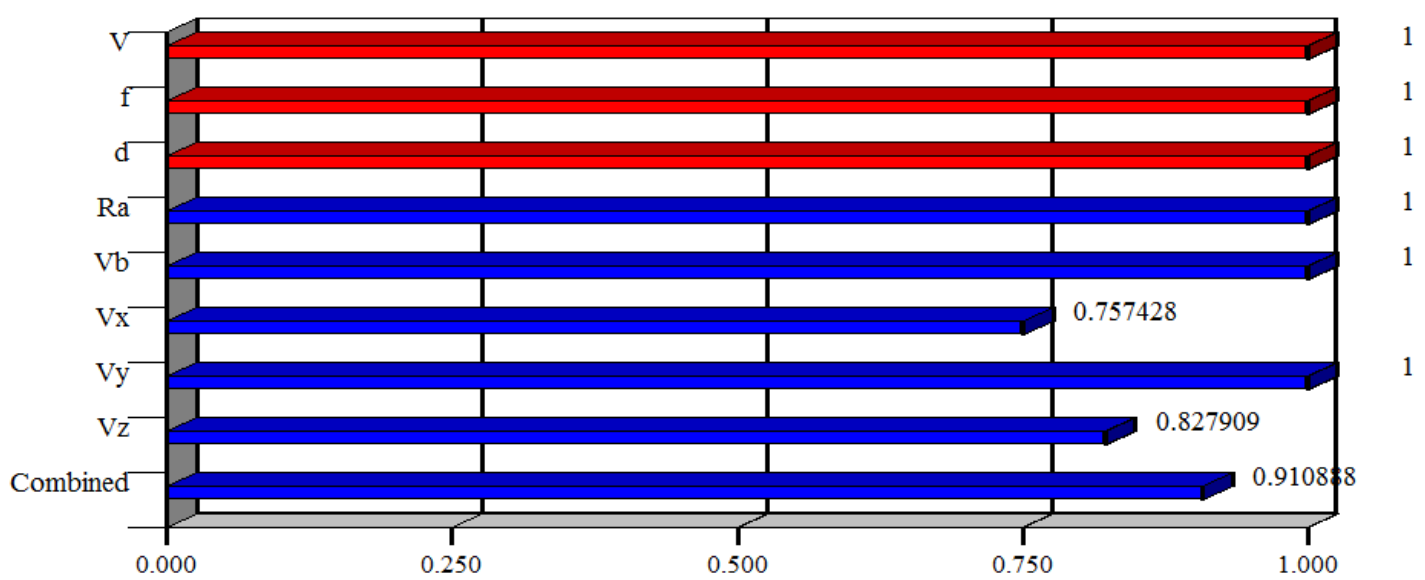

Figure 4. Bar graph of desirability. 


\section{Effect on Vibration Signals with Progressive Tool Wear}

Figure 5 shows the deviation in acceleration respect to progressive flank wear. It is seen that acceleration signals in all direction is increasing as tool wear increases. Figure 6 shows relationship of flank wear with cutting time. Figure 56 , signify the distinct wear zone; initial break-down, uniform, and rapid wear. During machining, tool engages with workpiece and tool cutting edge wears out rapidly at the beginning of its use. The acceleration in this stage suddenly increases and which is accurately detected by the accelerometer. Then wear take place at uniform rate. In rapid wear zone, cutting edge wears out faster rate due to higher normal pressure and temperature. This result in plastic flow and catastrophic failure of tool. It is seen that acceleration amplitude responds greatly to catastrophic failure.

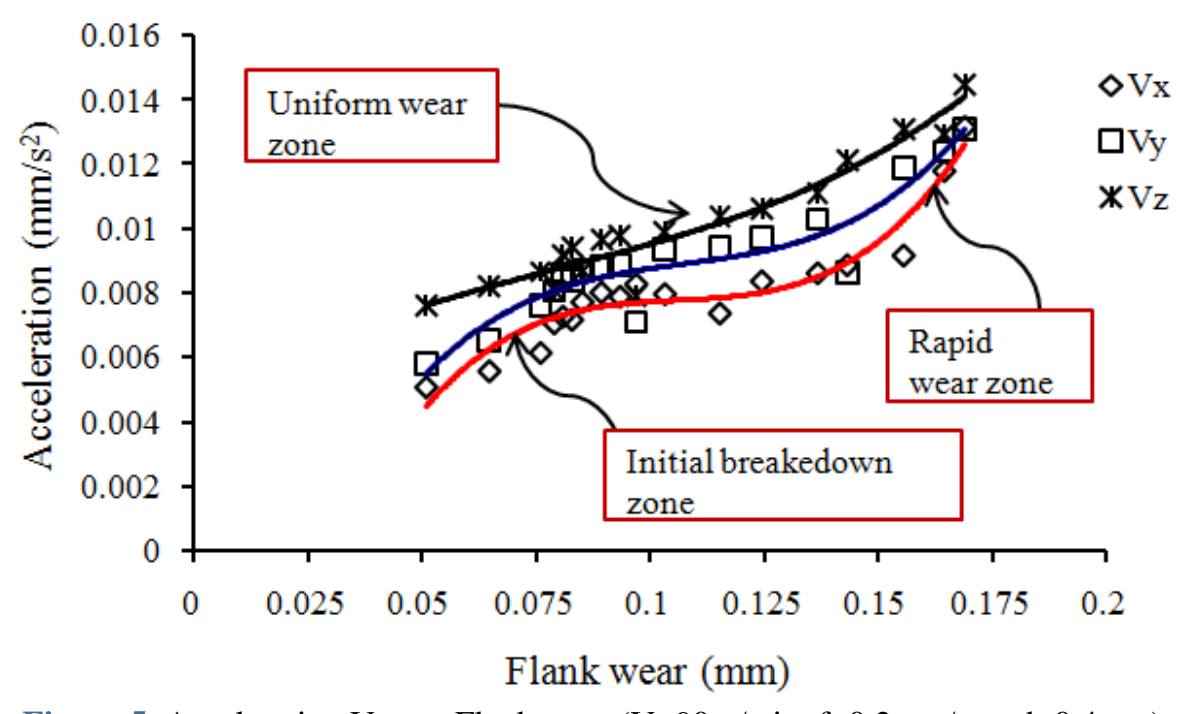

Figure 5. Acceleration Versus Flank wear (V=90m/min, $f=0.2 \mathrm{~mm} / \mathrm{rev}, \mathrm{d}=0.4 \mathrm{~mm})$.

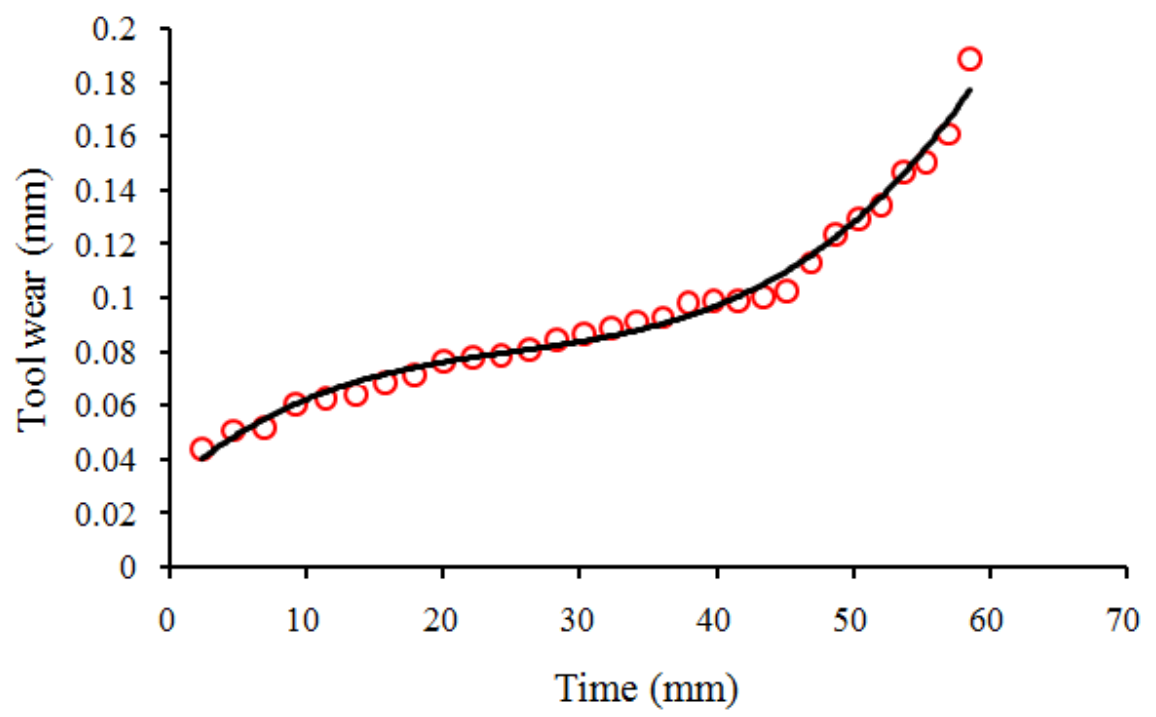

Figure 6. Tool wear Versus Time ( $\mathrm{V}=120 \mathrm{~m} / \mathrm{min}, \mathrm{f}=0.3 \mathrm{~mm} / \mathrm{rev}, \mathrm{d}=0.3 \mathrm{~mm})$.

From Figure 7(a-c), it very well may be seen that tool vibration signals are random in nature. The higher tool acceleration is seen in tangential direction compare with acceleration in other two directions. The pattern of accelerations is observed in fluctuating in nature in radial, feed and tangential directions. When turning with new cutting edge, the high acceleration peaks are found in lower (up-to $1100 \mathrm{~Hz}$ ) and higher frequency zone (up-to $15 \mathrm{kHz}$ ). In chosen machining parameters, 12 sets out of twenty designed condition, the greatest value of acceleration amplitude is seen in the range of $3 \mathrm{kHz}-10 \mathrm{kHz}$. Table 8 represent observed frequency range for different cutting condition. For cutting speed $150 \mathrm{~m} / \mathrm{min}$, feed $0.4 \mathrm{~mm} / \mathrm{rev}$ and depth of cut $0.2 \mathrm{~mm}$, a continuous chip formation take place near the location of sensor placed. The chips beating the sensor in every rotation and therefore unexpected increase in acceleration value is observed (see Figure 8). 
Table 8. Frequency range for various cutting conditions.

\begin{tabular}{cccccccc}
\hline \multirow{2}{*}{ Run } & \multicolumn{3}{c}{ Trial set } & & \multicolumn{3}{c}{ Frequency band $\mathrm{Hz}$} \\
\cline { 2 - 4 } \cline { 6 - 8 } & $\mathrm{V}$ & $\mathrm{f}$ & $\mathrm{d}$ & & $\mathrm{V}_{\mathrm{x}}$ & $\mathrm{V}_{\mathrm{y}}$ & $\mathrm{V}_{\mathrm{z}}$ \\
\hline 1 & 150 & 0.2 & 0.2 & & $44-9520$ & $26-10695$ & $65-10750$ \\
2 & 150 & 0.4 & 0.2 & & $121-8646$ & $76-11180$ & $96-12810$ \\
3 & 180 & 0.3 & 0.3 & & $16-11160$ & $45-11940$ & $16-10880$ \\
6 & 90 & 0.4 & 0.4 & & $96-9562$ & $35-14130$ & $11-14260$ \\
10 & 120 & 0.5 & 0.3 & & $397-6453$ & $353-6512$ & $107-8342$ \\
16 & 120 & 0.3 & 0.3 & & $59-6550$ & $76-6652$ & $172-8970$ \\
14 & 60 & 0.3 & 0.3 & & $42-8260$ & $23-8760$ & $32-9320$ \\
20 & 120 & 0.3 & 0.3 & & $323-6956$ & $365-6552$ & $101-9012$ \\
\hline
\end{tabular}

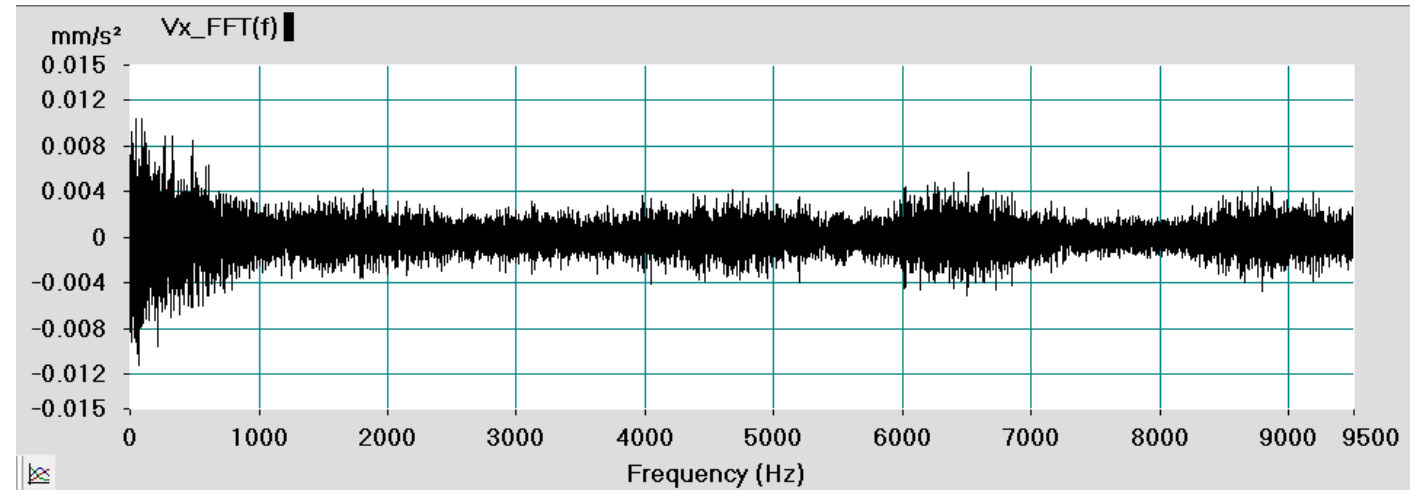

(a)

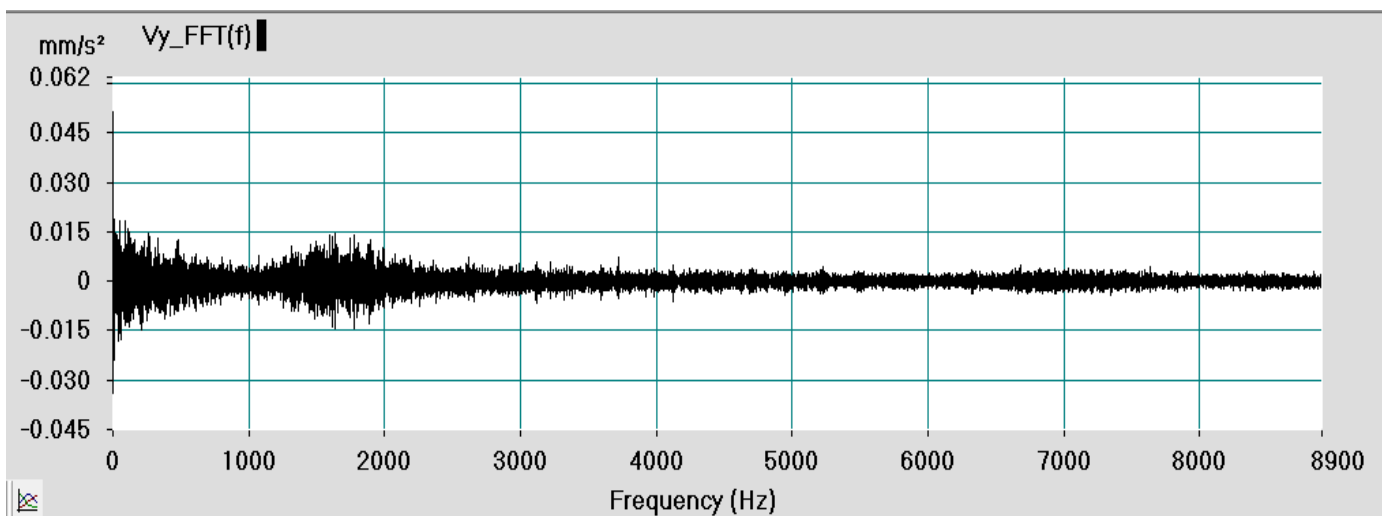

(b)

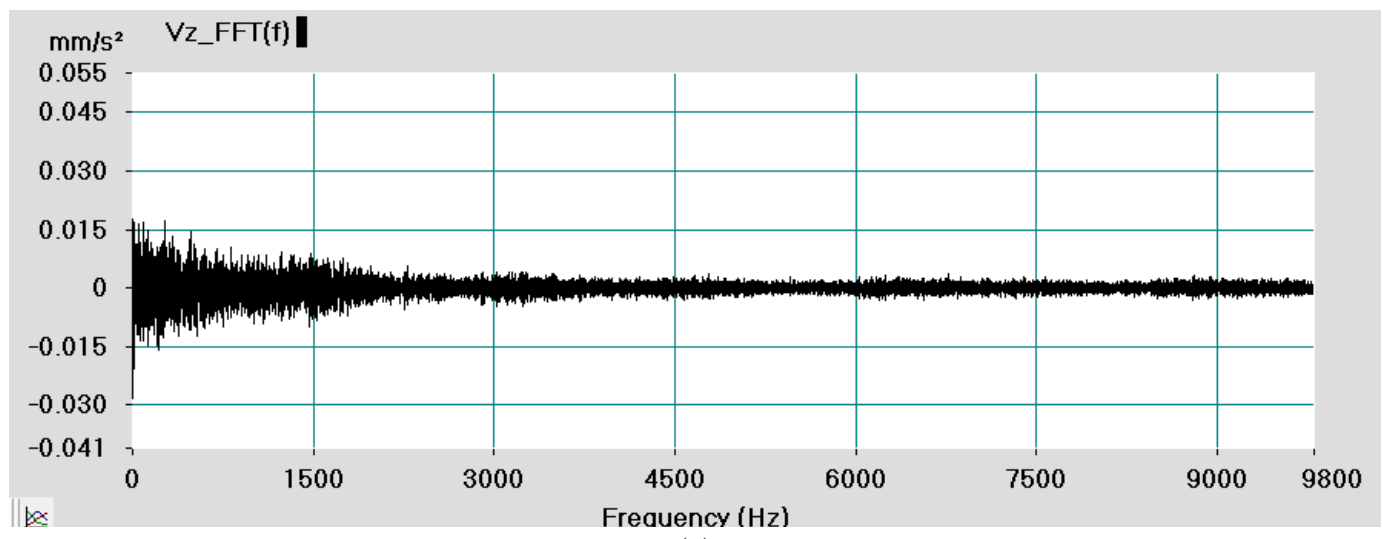

(c)

Figure 7. Vibration response at $V=90 \mathrm{~m} / \mathrm{min}, \mathrm{f}=0.4 \mathrm{~mm} / \mathrm{rev}, \mathrm{d}=0.4 \mathrm{~mm}$ and $\mathrm{V}_{\mathrm{b}}=0.078 \mathrm{~mm}$ (a) $\mathrm{V}_{\mathrm{x}}$ (b) $\mathrm{V}_{\mathrm{y}}$ (c) $\mathrm{V}_{\mathrm{z}}$. 


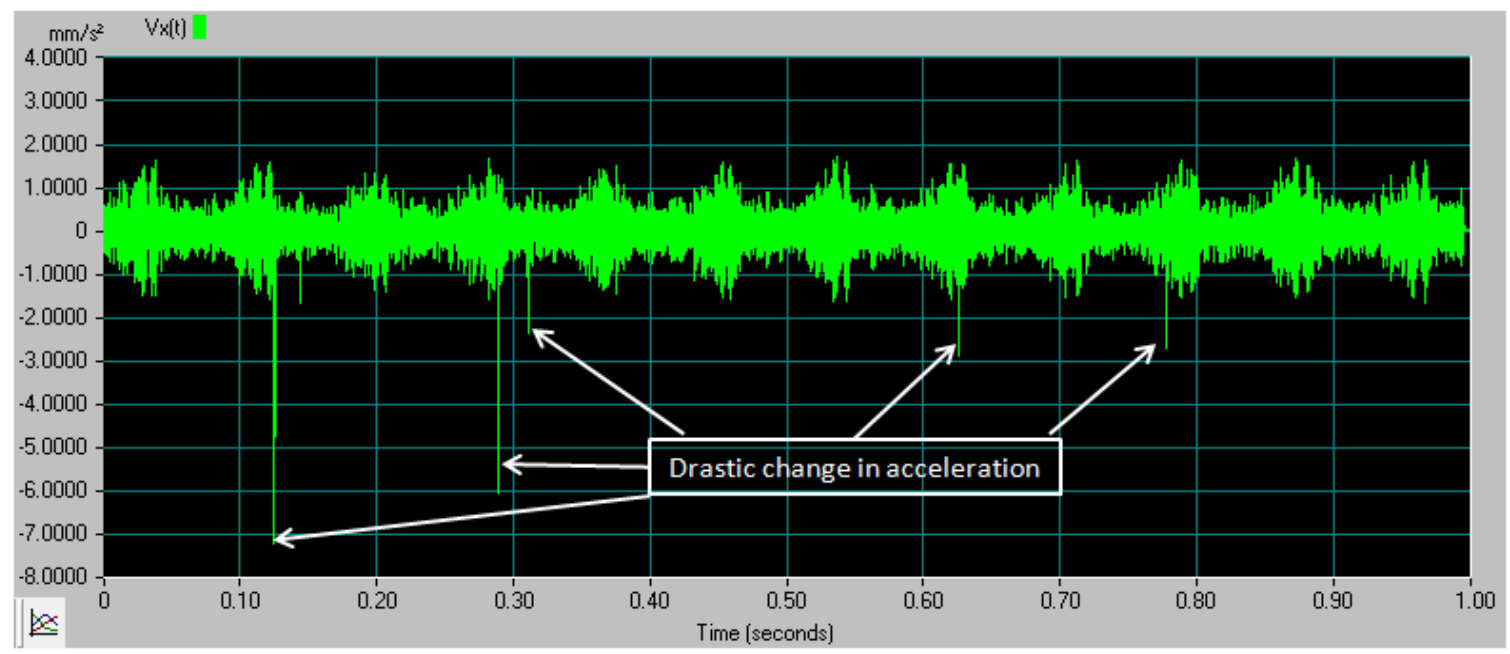

Figure 8. Drastic change in accleration.

Impact of Tool Wear on Surface Roughness

The surface quality of finished part with respect to time is shown in Figure 10. At the beginning of machining process, the surface roughness value decreases with the time. This happens due to sharp edge of tool. Then, gradual improvement in surface finish is seen because of uniform tool wear. It is to be noted that, in hard turning, good surface finish is observed as tool wear progresses up-to certain value. Similar research is reported by D’Mello et al. [21] and Che-Haron et al. [26].

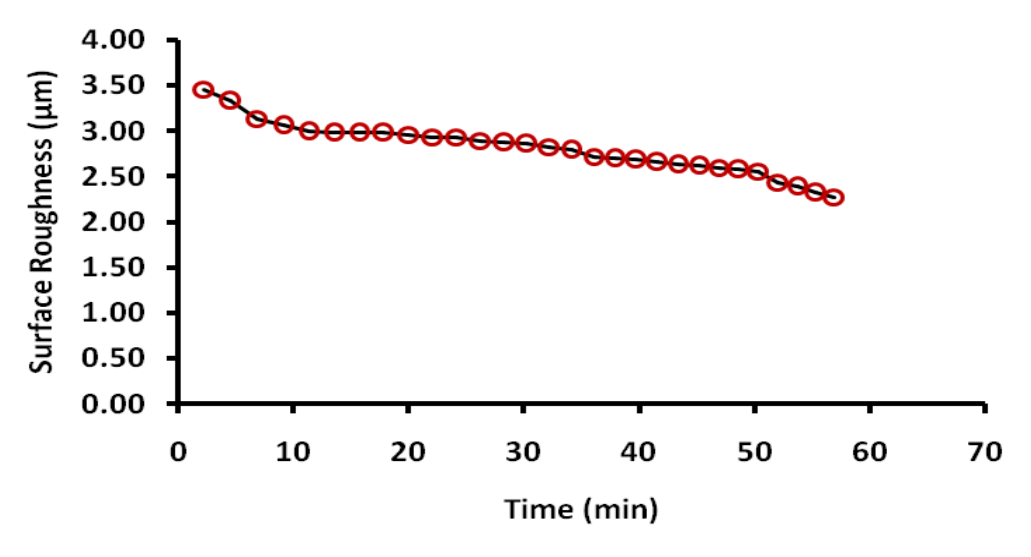

Figure 10. Surface roughness Versus Time $(V=120 \mathrm{~m} / \mathrm{min}, \mathrm{f}=0.3 \mathrm{~mm} / \mathrm{rev}, \mathrm{d}=0.3 \mathrm{~mm})$.

\section{CONCLUSIONS}

In the present work, an exploratory examination has been done so as to build up the relationship between cutting parameters, flank wear and surface roughness. Also, ANOVA is presented and some concluding are outlined as follows,

- ANOVA demonstrates that the feed has the highest statistical significance followed by cutting speed though the depth of cut discovered less noteworthy on surface roughness Ra.

- The most noteworthy factual criticalness on vibration in the feed direction $\left(\mathrm{V}_{\mathrm{x}}\right)$ followed by $\mathrm{f}^{2}$ (feed) while the profundity depth of cut discovered less impact.

- Analysis for the vibration in a radial direction $\left(\mathrm{V}_{\mathrm{y}}\right)$ showed that feed has the strong statistical significance followed by the depth of cut while the cutting speed observed less significant on the vibration in $\mathrm{Vy}$.

- When considering the vibration of a cutting tool in a tangential direction $\left(V_{z}\right)$, the term cutting speed $\left(V^{2}\right)$ has the elevated impact followed by term feed $\left(\mathrm{f}^{2}\right)$ and depth of cut $\left(\mathrm{d}^{2}\right)$. The terms cutting speed and depth of cut showed negligible influence on $\mathrm{V}_{\mathrm{z}}$. On the other hand, the interaction $\mathrm{V} \times \mathrm{f}$ and $\mathrm{f} \times \mathrm{d}$ are significant, while interaction $\mathrm{V} \times \mathrm{d}$ was found to be insignificant.

- Cutting speed has the most grounded on tool wear than feed and depth of cut. When turning hard materials, increased cutting speed increases tool wear drastically due to increase in temperature in a contact zone.

- Tool vibration in tangential direction $\left(\mathrm{V}_{\mathrm{z}}\right)$ is found higher than the vibrations $\mathrm{V}_{\mathrm{x}}$ and $\mathrm{V}_{\mathrm{z}}$.

- The surface roughness value decreases drastically with the time due sharp edges of the cutting tool. Better surface finish is observed as tool wear progresses up-to $0.136 \mathrm{~mm}$. 
- Vibrations especially measured in radial directions are conspicuously influenced by the depth of cut followed by feed value. However, tool vibrations measured in tangential direction seen to decrease with increase in cutting speed.

- Regression coefficient $\left(\mathrm{R}^{2}\right)$ value is discovered near 0.9 which indicate models are appropriate and provides a superb rationalization of the link between cutting parameters and tool vibrations.

- High vibrations are seen in the range of $3 \mathrm{kHz}-16 \mathrm{kHz}$. The frequency has varying nature for variable cutting parameter. However, unexpected acceleration bigger values are observed when continuous chip formation started.

\section{ACKNOWLEDGEMENTS}

The authors are grateful to University Research Cell, SP Pune University, India for providing research fund, Sanction No. OSD/BCUD/303/2016 and the Department of Mechanical Engineering, VIIT, Pune, India, for allowing laboratory facility to carry out the research work

\section{REFERENCES}

[1] Shihab SK, Khan ZA, Mohammad A, Siddiquee AN. A review of turning of hard steels used in bearing and automotive applications. Production \& Manufacturing Research: An Open Access Journal. 2014;2(1):24-49.

[2] Chinchanikar S, Choudhury SK. Machining of hardened steel-Experimental investigations, performance modeling and cooling techniques: A review. International Journal of Machine Tools \& Manufacture. 2015;89:95-109.

[3] Kasim NA, Nuawi MZ, Ghani JA, Rizal M, Ahmad MAF and Che Haron CH, Cutting tool wear progression index via signal element variance. Journal of Mechanical Engineering and Sciences, 2019;13(1), 4596-4612.

[4] Huang Y, Liang SY. Modeling of Cutting Forces under Hard Turning Conditions Considering Tool Wear Effect. Transactions of the ASME. 2015;262/127:262-270.

[5] Shokrani A, Dhokia V, Newman ST. Environmentally conscious machining of difficult-to-machine materials with regard to cutting fluids. International Journal of Machine Tools \& Manufacture. 2012;57;83-101.

[6] Chinchanikar S, Choudhury SK. Wear behaviors of single-layer and multi-layer coated carbide inserts in high speed machining of hardened AISI 4340 steel. Journal of Mechanical Science and Technology. 2013;27(5):1451-1459

[7] Zainol A and Yazid MZA, The effect of portable MQL applicator onto carbide insert during turning Inconel 718. Journal of Mechanical Engineering and Sciences, 2018;12(2), 3605-3613.

[8] Mia M, Dhar NR. Prediction and optimization by using SVR, RSM and GA in hard turning of tempered AISI 1060 steel under effective cooling condition. Neural Computing and Applications. 2017; 1-22.

[9] Patil NK, Gopalakrishna K, Sangmesh B, Sudhakar K, Vijaykumar GC, Performance studies on cryogenic treated carbide cutting tool for turning of AISI304 steel. Journal of Mechanical Engineering and Sciences, 2018;12(3), 3927 - 3941.

[10] Suresh R, Basavarajappa S, Samuel GL. Some studies on hard turning of AISI 4340 steel using multilayer coated carbide tool. Measurement. 2012;45:1872-1884.

[11] Zahia H, Belbah A, Yallese MA, Mabrouki T, Rigal JF. On the prediction of surface roughness in the hard turning based on cutting parameters and tool vibrations. Measurement. 2013;46:1671-1681.

[12] Upadhyay V, Jain PK, Mehta NK. In-process prediction of surface roughness in turning of Ti-6Al-4V alloy using cutting parameters and vibration signals. Measurement. 2013;46:154-160.

[13] Asilturk I, Akkus H. Determining the effect of cutting parameters on surface roughness in hard turning using the Taguchi method. Measurement. 2011;44:1697-1704.

[14] Bouzid L, Yallese MA, Chaoui K, Mabrouki T, Boulanouar L. Mathematical modeling for turning on AISI 420 stainless steel using surface response methodology. Journal of Engineering Manufacture. 2015;229(1):45-61.

[15] Bhuiyan MSH, Choudhury IA. Investigation of Tool Wear and Surface Finish by Analyzing Vibration Signals in Turning Assab705 Steel. Machining Science and Technology. 2015;19(2):236-261.

[16] Neslusan M, Micieta B, Micietova A, Cillikova M, Mrkvica I. Detection of tool breakage during hard turning through acoustic emission at low removal rates. Measurement. 2015;70:1-13.

[17] Ambhore N, Kamble D, Chinchanikar S, Wayal V. Tool condition monitoring system: A review. Materials Today: Proceedings. 2015;2:3419-3428.

[18] Teti R, Jemielniak K, O’Donnell G, Dornfeld D. Advanced monitoring of machining operations. CIRP Annals - Manufacturing Technology. 2010;79:717-739.

[19] Gonzalez-Laguna A, Barreiro J, Fernandez-Abia A, Alegre E. Gonzalez- Castro V. Design of a TCM system based on vibration signal for metal turning processes. Procedia Engineering. 2015;132:405 - 412.

[20] Kilundu B, Dehombreux P, Chiementin X. Tool wear monitoring by machine learning techniques and singular spectrum analysis. Mechanical Systems and Signal Processing. 2011;25:400-415.

[21] Grynal D, Srinivasa PP, Puneet NP, Ning F. Surface roughness evaluation using cutting vibrations in high speed turning of Ti6Al-4V -an experimental approach. International Journal of Machining and Machinability of Materials. 2016;18(3):288-312.

[22] Prasad BS, Babu MP. Correlation between vibration amplitude and tool wear in turning: Numerical and experimental analysis. Engineering Science and Technology an International Journal. 2017;20:197-211. 
[23] Ozel T, Hsu T, Zeren E. Effects of cutting edge geometry, workpiece hardness, feed rate and cutting speed on surface roughness and forces in finish turning of hardened AISI H13 steel. International Journal Advanced Manufacturing Technology. 2005;25:262-269.

[24] Montgomery DC, Design and Analysis of experiments, 6th ed. John Wiley and Sons India Pvt. Ltd.;2014.

[25] Boy M, Yasar N, Ciftci I. Experimental investigation and modelling of surface roughness and resultant cutting force in hard turning of AISI H13 steel. IOP Conference Series: Materials Science and Engineering. 2016;161:1-10.

[26] Che-Haron $\mathrm{CH}$, Jawaid A. The effect of machining on surface integrity of titanium alloy Ti-6Al-4V. Journal of Materials Processing Technology. 2005;166(2):188-192. 